\title{
The association between sleep patterns and overweight/obesity in Chinese children: a cross- sectional study
}

This article was published in the following Dove Press journal:

Neuropsychiatric Disease and Treatment

24 August 2015

Number of times this article has been viewed

\author{
Bin Zhangl,* \\ Yanli $\mathrm{Hao}^{2, *}$ \\ Jiangyan Zhou' ${ }^{1,3}$ \\ Fujun Jia' \\ Xueli $\mathrm{Li}^{\prime}$ \\ Yi Tang' \\ Huirong Zheng' \\ 'Guangdong General Hospital, \\ Guangdong Academy of Medical \\ Sciences, Guangdong Mental Health \\ Centre, ${ }^{2}$ Department of Human \\ Anatomy, Guang Zhou Medical \\ University, ${ }^{3}$ Department of Psychiatry, \\ Southern Medical University, \\ Guangzhou, People's Republic of \\ China \\ *These authors contributed equally \\ to this work
}

Objective: This study evaluated the association between sleep patterns and the risk of being overweight/obese in Chinese children.

Methods: A total of 3,086 children (1,608 boys and 1,478 girls) between 7 and 14 years of age and studying in primary schools were recruited as eligible study participants in this study. We collected the information about children regarding sleep patterns, body height and weight, insomnia, healthy status, time allocation of daily activities, and demographic characteristics using a parental-reported questionnaire.

Results: Overweight/obese children were younger, predominantly male, and more prone to have suffered from illness in the past 12 months compared to normal-weight peers. They were also less prone to compensate for sleep deficits during weekends ( $47.6 \%$ vs $39.1 \% ; \chi^{2}=11.637$, $P<0.001)$ and holidays (52.0\% vs $\left.42.0 \% ; \chi^{2}=16.057, P<0.001\right)$. Sleep duration on weekdays did not affect the risk of being overweight/obese. The adjusted odds ratios for overweight/ obesity (noncompensated) group using the compensated group as a reference were 1.197 (95\% confidence interval [CI]: 1.004-1.493) during weekends and 1.309 (95\% CI: 1.052-1.630) during holidays.

Conclusion: Compensation for sleep deficits on non-weekdays may ameliorate the risk of being overweight/obese in Chinese children. Moreover, no significant association between the risk of being overweight/obese and sleep duration on weekdays was demonstrated in the current study, which may be due to pervasive sleep insufficiency on weekdays in Chinese children.

Keywords: Chinese children, overweight/obese, sleep duration, sleep compensation

\section{Introduction}

Obesity is one of today's most blatantly visible, yet most neglected, worldwide public health epidemic across all ages, sexes, and ethnic groups. Nonetheless, childhood obesity may require more attention than adult obesity because childhood obesity negatively impacts the current health of children and also influences their future health. ${ }^{1}$ Moreover, the global prevalence of overweight and obese children escalated from $4.2 \%$ in 1990 to $6.7 \%$ in 2010 , a rate faster than that for adults. ${ }^{2}$ The increase in the prevalance of pediatric obesity can be more dramatic in some transition societies. ${ }^{3}$ For example, the People's Republic of China is a typical transition society with rapid economic development since the economic reform in the 1970s, which resulted in a transition to a more high-fat, high-energy-dense, and low-fiber diet. ${ }^{4,5}$ Not surprisingly, the Chinese National Survey on Students' Constitution and Health reported that the prevalence of childhood overweight and obesity escalated progressively in recent decades and reached $19.2 \%$ in children aged $7-18$ years in $2010 .^{6}$ Pediatric obesity poses a major risk for serious
Guangdong General Hospital, Guangdong Academy of Medical Science, Guangdong Mental Health Centre, No I23,

Hui Fu Xi Road, Guang Zhou 510120,

People's Republic of China

Tel +86208188 8553

Fax +862081862664

Email zhang73bin@hotmail.com
Neuropsychiatric Disease and Treatment 2015:II 2209-2216 
diet-related diseases, including obstructive sleep apnea, diabetes mellitus, cardiovascular disease, hypertension and stroke, and some negative psychological outcomes, including low self-esteem, depression, and stigmatization. ${ }^{7,8}$

Obesity is influenced by many factors, such as heredity, early life influences, familial dietary behaviors, little physical activity, and sleep. ${ }^{9}$ The primary strategies of obesity prevention mainly focus on the basic balance between food intake (calories) and energy expenditure (physical activity), but relevant interventions produced minimal positive weightreduction outcomes in children. ${ }^{8}$ Therefore, other potential contributory factors, such as sleep, have been considered. Systematic reviews have clearly demonstrated a positive relationship between short sleep duration and pediatric obesity. ${ }^{10-12}$ It is hypothesized that short sleep duration can result in an energy imbalance by disturbing the levels of several hormones, including leptin, ghrelin, insulin, cortisol, and growth hormone. ${ }^{13}$ Moreover, the concentrations of some sleep-regulating hormones (serotonin and melatonin) can also be disturbed by sleep curtailment. It is believed that serotonin can cause the release of cholecystokinin (a satiety hormone) in the brain, ${ }^{14}$ and melatonin appears to be a promising supplement for battling obesity. ${ }^{15}$ Sleep duration in humans has shown an overall decline for over a century; thus, the individuals in modern society sleep relatively fewer hours. ${ }^{16}$ Furthermore, $43 \%$ of the American population sleeps less than 7 hours on workdays compared with $30 \%$ during the weekend. ${ }^{17}$ This report also demonstrates sleep compensation during the weekend, which creates a possible recovery effect after 5 consecutive working days of shorter sleep duration. In parallel, the majority of children sleeps fewer hours on weekdays during the school term and has a tendency to prolong their sleep duration during weekends. ${ }^{18-22}$ Two recent studies in East Asia (Hong Kong and Korea) have supported the notion that this sleep compensation pattern may partially ameliorate the risk of pediatric overweight/obesity. ${ }^{21,22}$

As the prevalence of childhood overweight and obesity has escalated progressively in recent decades in the People's Republic of China, this study aimed to evaluate the association between sleep patterns and the risk of being overweight/ obese in Chinese children.

\section{Methods}

\section{Study design and sample}

Data for this analysis were obtained from a large-scale epidemiological study of sleep patterns in Guangzhou city from September to December 2009. The Independent Ethics Committee of Guangdong Mental Health Center approved this study, and procedures were performed in accordance with the Declaration of Helsinki. The study design and procedures are described in detail elsewhere and are summarized here. ${ }^{23}$ The total population in the present study was 4,036 children. All the children were 7-14 years of age and in grades 1-6, and were from five randomly selected elementary schools in Guangzhou city. An envelope containing a sleep questionnaire, an invitation letter, and a written informed consent on behalf of the children was distributed through the elementary schools to be completed by the parents. All 4,036 children returned their questionnaires. The following respondents were excluded: questionnaires that contained grossly incomplete or missing data for bedtime or get-up time, body height or weight ( $\mathrm{n}=843$ ), or answered less than $70 \%$ questions $(n=149)$. Forty-two respondents overlapped in two of the above situations. Therefore, $950(n=843+[149-42])$ respondents were excluded. The remaining 3,086 respondents (76.4\% of the total population, 1,608 boys and 1,478 girls) represented the eligible study population.

\section{Instrument}

The sleep questionnaire was designed to collect information on sleep-related factors based on parental observation of their children during the previous 12 months. It consisted of the following items: demographic characteristics, body height and weight, sleep patterns, insomnia, healthy status, time allocation of daily activities (eg, school schedules, homework, reading for pleasure, television viewing, computer games, Internet surfing, talking on the phone, physical exercise, transportation, extracurricular activities, eating 1 hour before bedtime), and some parental information. Two questions pertaining to sleep were asked for three periods (weekday during school terms, weekend during school terms, and long holidays [summer holiday and winter holiday]) to determine children's sleep patterns: "What time do you usually go to bed?" and "What time do you usually get up?"

\section{Study variables \\ Weight categories}

We calculated body mass index (BMI, weight in kilograms divided by square of height in meters) based on parental reports of anthropometric data as the index of overweight and obesity in childhood. The Group of China Obesity Force established age- and sex-specific BMI cutoff points for overweight and obesity in Chinese children that are parallel to the international BMI reference standards proposed by the International Obesity Task Force (Table 1). ${ }^{24}$ The age- and sexspecific prevalence of overweight and obesity according to 
Table I Age- and sex-specific body mass index (BMI) cutoff points for overweight and obese Chinese children

\begin{tabular}{|c|c|c|c|c|c|c|c|c|}
\hline & $\begin{array}{l}7 \text { years } \\
(n=503)\end{array}$ & $\begin{array}{l}8 \text { years } \\
(n=429)\end{array}$ & $\begin{array}{l}9 \text { years } \\
(n=460)\end{array}$ & $\begin{array}{l}10 \text { years } \\
(n=667)\end{array}$ & $\begin{array}{l}\text { II years } \\
(n=577)\end{array}$ & $\begin{array}{l}\text { I } 2 \text { years } \\
(n=386)\end{array}$ & $\begin{array}{l}13 \text { years } \\
(n=58)\end{array}$ & $\begin{array}{l}14 \text { years } \\
(n=6)\end{array}$ \\
\hline Male & $n=250$ & $n=186$ & $n=24 I$ & $n=347$ & $n=331$ & $n=197$ & $n=31$ & $n=3$ \\
\hline \multicolumn{9}{|l|}{ Overweight } \\
\hline Cutoff points & $17.4-19.19$ & $18.1-20.29$ & $18.9-21.39$ & $19.6-22.49$ & $20.3-23.59$ & $21.0-24.69$ & $21.9-25.69$ & $22.6-26.39$ \\
\hline Prevalence, n (\%) & $39(15.6)$ & $17(9.1)$ & $32(13.3)$ & $59(17.0)$ & $61(18.4)$ & $16(8.1)$ & $I(16.1)$ & 0 \\
\hline \multicolumn{9}{|l|}{ Obesity } \\
\hline Cutoff points & $\geq 19.2$ & $\geq 20.3$ & $\geq 21.4$ & $\geq 22.5$ & $\geq 23.6$ & $\geq 24.7$ & $\geq 25.7$ & $\geq 26.4$ \\
\hline Prevalence, n (\%) & $54(21.6)$ & $34(18.3)$ & $34(14.1)$ & $37(10.7)$ & $23(6.9)$ & $15(7.6)$ & I (9.6) & 0 \\
\hline Female & $\mathrm{n}=253$ & $n=243$ & $n=219$ & $\mathrm{n}=320$ & $n=246$ & $n=189$ & $n=27$ & $n=3$ \\
\hline \multicolumn{9}{|l|}{ Overweight } \\
\hline Cutoff points & $17.2-18.89$ & $18.1-19.89$ & 19.0-20.99 & $20.0-22.09$ & $21.1-23.29$ & $21.9-24.49$ & $22.6-25.59$ & $23.0-26.29$ \\
\hline Prevalence, n (\%) & 29 (II.5) & $22(9.1)$ & $16(7.3)$ & $30(9.4)$ & $14(5.7)$ & $5(2.6)$ & $2(7.4)$ & 0 \\
\hline \multicolumn{9}{|l|}{ Obesity } \\
\hline Cutoff points & $\geq 18.9$ & $\geq 19.9$ & $\geq 21.0$ & $\geq 22.1$ & $\geq 23.3$ & $\geq 24.5$ & $\geq 25.6$ & $\geq 26.3$ \\
\hline Prevalence, n (\%) & 40 (I5.7) & $38(15.6)$ & $16(7.3)$ & $29(9.1)$ & $6(2.4)$ & 0 & I (3.7) & 0 \\
\hline
\end{tabular}

local standards are shown in Table 1. A total of $225(13.99 \%)$ boys and $118(7.98 \%)$ girls were overweight $\left(\chi^{2}=24.158\right.$, $P<0.001)$, and $198(12.31 \%)$ boys and $130(8.80 \%)$ girls were obese $\left(\chi^{2}=10.033, P<0.01\right)$. Boys were more prone to being overweight and obese than girls (Table 1).

\section{Sleep durations}

Sleep durations (hours) were calculated as the difference between get-up time and bedtime, and three sleep parameters were analyzed: 1) weekday sleep duration during school terms; 2) weekend sleep duration during school terms; and 3) sleep duration during long holidays. In this study, sleep duration was categorized as follows: $\leq 8.00$ hours, 8.01-9.00 hours, 9.01-10.00 hours, and $>10$ hours because a previous study suggested that the sleep duration reference could be treated as $>10$ hours in elementary school children. ${ }^{25}$ Moreover, sleep compensation was determined by calculating the extent of divergence in sleep duration between weekdays and weekends (weekend divergence) using the equation: (weekend sleep duration - weekday sleep duration)/weekday sleep duration $\times 100 \%$. The extent of divergence between weekdays and holidays (holiday divergence) was calculated using the equation: (holiday sleep duration - weekday sleep duration)/weekday sleep duration $\times 100 \%$. A weekend divergence $\geq 10 \%$ or holiday divergence $\geq 10 \%$ was defined as sleep compensation during a weekend or holiday, respectively.

\section{Covariates}

We considered the following variants as potential confounders for the hypothesized relationships between overweight/ obese and sleep patterns based on previous studies: $3,6,8-10,18-22,25$ sex, age, full-term birth, breast feeding, healthy status, insomnia, time allocation of daily activities (details are given in the "Instrument" section), paternal information (marriage status, age, and education level), house area, and family income. Three subtypes of insomnia - difficulty initiating sleep, difficulty maintaining sleep, and early morning awakening - were defined in the present study when the prevalence was three or more occurrences per week. Health status was evaluated using some common childhood illnesses (eg, allergic rhinitis, asthma, nasosinusitis, tympanitis, tonsillitis, and throat inflammation). Children with frequent illnesses ( $\geq 3$ times in the previous 12 months) were regarded as unhealthy.

\section{Statistical analysis}

Data are presented as the mean \pm standard deviation for continuous variables and numbers or percentages for categorical variables. An unpaired $t$-test (parametric data) and the Mann-Whitney $U$-test (nonparametric data) were used to compare age, time allocation of daily activities, parental age, house area, family income, and sleep patterns. A chi-squared test was used to compare differences in sex, full-term birth, breast feeding, healthy status, paternal marriage status and education level, insomnia, and sleep compensation. Multiple logistic regression models were used to examine the relationship between sleep patterns (sleep compensation and sleep duration [ $\leq 8.00$ hours, 8.01-9.00 hours, 9.01-10.00 hours, and $>10$ hours]) and the state of being overweight/obese, adjusting for age, sex, healthy status, and mother's age. These covariates were chosen on the basis of the preliminary statistical results of the present study. The effect of interaction between weekday and weekend sleep duration and weekday and holiday sleep duration on being overweight/obese was 
investigated by adding interaction terms (ie, weekday sleep duration $\times$ weekend sleep duration; weekday sleep duration $\times$ holiday sleep duration) in the logistic models. These models were established to determine whether the effect of weekday sleep duration on overweight/obese would vary with weekend and holiday sleep duration. A two-sided 5\% level of significance was considered significant for all the statistical tests. All the statistical procedures were performed using Statistical Package for the Social Sciences 16.0 for Windows (SPSS Inc., Chicago, IL, USA).

\section{Results}

\section{Analysis of excluded subjects}

Data on sleep duration and BMI data were available for $3,086(76.4 \%)$ of 4,036 children. There were no significant differences in demographic characteristics, body weight and height, sleep patterns, insomnia, healthy status, daily activities, paternal marriage status, and age between the 3,086 study subjects and 950 excluded subjects in the present analysis. However, the parents of the study subjects were more prone to have college or above education levels than the excluded subjects (father: $21.5 \%$ and $15.6 \%$, respectively; $\chi^{2}=14.957, P<0.001$; mother: $17.6 \%$ and $11.3 \%$, respectively; $\left.\chi^{2}=21.558, P<0.001\right)$.

\section{Sample characteristics}

Table 2 shows the sociodemographic characteristics and daily activities of overweight/obese children $(n=671,21.74 \%)$ and normal-weight children. The two groups shared similar time allocations of their daily activities. The larger BMI in the overweight/obese children was due to their higher body weight and shorter height. Overweight/obese children were younger, predominantly male, and more prone to suffering from illness in the recent 12 months than their normal-weight peers.

\section{Sleep patterns and insomnia}

Table 3 presents the sleep patterns of overweight/obese children and normal-weight children. The two groups shared similar bed times, get-up times, and sleep duration during weekdays. Overweight/obese children tended to get up earlier and had shorter sleep durations during weekends and holidays compared to their normal-weight peers, and they went to bed earlier during holidays. Both groups prolonged

Table 2 Sample characteristics between Chinese normal-weight and overweight/obese children aged 7-I4 years

\begin{tabular}{|c|c|c|c|c|}
\hline & $\begin{array}{l}\text { Normal weight } \\
(n=2,4 \mid 5)\end{array}$ & $\begin{array}{l}\text { Overweight/obese } \\
(n=67 I)\end{array}$ & Statistics & P-value \\
\hline Age, years & $9.66 \pm 1.67$ & $9.00 \pm 1.61$ & $t=7.897$ & $P=0.000$ \\
\hline Male sex, \% & 48.5 & 63.1 & $\chi^{2}=44.718$ & $P=0.000$ \\
\hline Height, cm & $|39.57 \pm| \mid .75$ & $|36.30 \pm 1| .96$ & $t=5.568$ & $P=0.000$ \\
\hline Weight, kg & $31.26 \pm 7.72$ & $42.27 \pm 9.28$ & $t=24.678$ & $P=0.000$ \\
\hline $\mathrm{BMI}, \mathrm{kg} / \mathrm{m}^{2}$ & $15.83 \pm 2.09$ & $22.66 \pm 3.87$ & $t=38.558$ & $P=0.000$ \\
\hline Breast feeding, \% & 75.7 & 77.1 & $\chi^{2}=0.712$ & $P=0.406$ \\
\hline Full-term birth, \% & 84.2 & 86.8 & $\chi^{2}=1.803$ & $P=0.290$ \\
\hline Suffering from illness three or more times in the previous 12 months, $\%$ & 11.3 & 16.3 & $\chi^{2}=9.257$ & $P=0.002$ \\
\hline Paternal marriage status (married), \% & 90.4 & 89.5 & $\chi^{2}=1.433$ & $P=0.231$ \\
\hline Father's age, years & $40.93 \pm 5.33$ & $40.56 \pm 5.44$ & $t=1.306$ & $P=0.192$ \\
\hline Mother's age, years & $37.5 I \pm 4.7 I$ & $37.01 \pm 4.08$ & $t=2.086$ & $P=0.067$ \\
\hline Father's education level (college or above), \% & 18.7 & 17.8 & $\chi^{2}=0.738$ & $P=0.835$ \\
\hline Mother's education level (college or above), \% & 15.0 & 16.5 & $\chi^{2}=0.703$ & $P=0.538$ \\
\hline House area ( $\geq 70$ sq meter), $\%$ & 45.7 & 44.6 & $\chi^{2}=0.550$ & $P=0.477$ \\
\hline Family income ( $\geq 5,000 \mathrm{RMB} /$ month), $\%$ & 34.1 & 32.9 & $\chi^{2}=0.546$ & $P=0.611$ \\
\hline \multicolumn{5}{|l|}{ Time allocation of daily activities } \\
\hline School schedule, hours & $5.27 \pm 2.87$ & $4.98 \pm 2.75$ & $t=\mathrm{I} .754$ & $P=0.080$ \\
\hline Homework, hours & $2.31 \pm 1.01$ & $2.32 \pm 0.99$ & $t=0.198$ & $P=0.843$ \\
\hline Reading for pleasure, hours & $0.76 \pm 0.69$ & $0.77 \pm 0.77$ & $Z=0.392$ & $P=0.695$ \\
\hline Television, computer games, or Internet surfing, hours & $2.02 \pm 3.38$ & $2.02 \pm 1.95$ & $Z=0.701$ & $P=0.484$ \\
\hline Talking on phone, hours & $0.23 \pm 0.60$ & $0.19 \pm 0.27$ & $Z=1.074$ & $P=0.283$ \\
\hline Physical exercise, hours & $0.85 \pm 1.06$ & $0.95 \pm 1.75$ & $Z=0.865$ & $P=0.387$ \\
\hline Transportation, hours & $0.61 \pm 0.76$ & $0.68 \pm 1.80$ & $Z=0.118$ & $P=0.906$ \\
\hline Other extracurricular activities, hours & $0.70 \pm 1.35$ & $0.61 \pm 0.80$ & $\chi^{2}=0.504$ & $P=0.614$ \\
\hline Eating I hour before bedtime, \% & 18.1 & 17.6 & $\chi^{2}=0.085$ & $P=0.770$ \\
\hline
\end{tabular}

Abbreviations: BMI, body mass index; RMB, Chinese dollar. 
Table 3 Sleep patterns and insomnia subtypes of Chinese normal-weight and overweight/obese children aged 7-14 years

\begin{tabular}{|c|c|c|c|c|}
\hline & $\begin{array}{l}\text { Normal weight } \\
(n=2,4 \mid 5)\end{array}$ & $\begin{array}{l}\text { Overweight/obese } \\
(n=671)\end{array}$ & Statistics & $P$-value \\
\hline \multicolumn{5}{|l|}{ Sleep patterns } \\
\hline \multicolumn{5}{|l|}{ Weekdays } \\
\hline Bedtime, hh:mm & $21: 55 \pm 1: 01$ & $21: 53 \pm 1: 03$ & $t=0.689$ & $P=0.491$ \\
\hline Get-up time, hh:mm & $7: 02 \pm 0: 42$ & $7: 07 \pm 0: 40$ & $t=1.247$ & $P=0.213$ \\
\hline Sleep duration, hours & $9.00 \pm 0.68$ & $9.03 \pm 0.68$ & $t=0.673$ & $P=0.501$ \\
\hline \multicolumn{5}{|l|}{ Weekends } \\
\hline Bedtime, hh:mm & $22: 55 \pm 01: 50$ & $22: 4 I \pm 03: 20$ & $t=0.683$ & $P=0.495$ \\
\hline Get-up time, hh:mm & $8: 50 \pm 01: 40$ & $8: 27 \pm 01: 31$ & $t=5.095$ & $P=0.000$ \\
\hline Sleep duration, hours & $9.89 \pm 0.96$ & $9.66 \pm 0.88$ & $t=5.00 \mathrm{I}$ & $P=0.000$ \\
\hline Weekend divergence ${ }^{\mathrm{a}}, \%$ & $10.37 \pm|2.8|$ & $7.51 \pm 11.98$ & $Z=3.713$ & $P=0.000$ \\
\hline Percentage of weekend divergence $\geq 10 \%, \%$ & 47.6 & 39.1 & $\chi^{2}=11.637$ & $P=0.000$ \\
\hline \multicolumn{5}{|l|}{ Holidays } \\
\hline Bedtime, hh:mm & $22: 44 \pm 03: 23$ & $22: 25 \pm 4: 28$ & $t=2.191$ & $P=0.029$ \\
\hline Get-up time, hh:mm & $9: 11 \pm 01: 45$ & $8: 45 \pm 01: 34$ & $t=5.069$ & $P=0.000$ \\
\hline Sleep duration, hours & $10.00 \pm 0.98$ & $9.74 \pm 0.98$ & $t=5.324$ & $P=0.000$ \\
\hline Holiday divergence ${ }^{b}, \%$ & $11.64 \pm 13.30$ & $8.46 \pm 13.33$ & $Z=5.066$ & $P=0.000$ \\
\hline Percentage of holiday divergence $\geq 10 \%, \%$ & 52.0 & 42.0 & $\chi^{2}=16.057$ & $P=0.000$ \\
\hline \multicolumn{5}{|l|}{ Insomnia subtypes } \\
\hline DIS ( $\geq 3 /$ week), \% & 2.7 & 3.5 & $\chi^{2}=0.923$ & $P=0.337$ \\
\hline DMS ( $\geq 3 /$ week), \% & 1.2 & 1.7 & $\chi^{2}=2.393$ & $P=0.122$ \\
\hline EMA ( $\geq 3 /$ week), $\%$ & 1.5 & 1.2 & $\chi^{2}=0.248$ & $P=0.618$ \\
\hline All of insomnia subtypes ( $\geq 3 /$ week), $\%$ & 3.5 & 4.2 & $\chi^{2}=0.757$ & $P=0.403$ \\
\hline
\end{tabular}

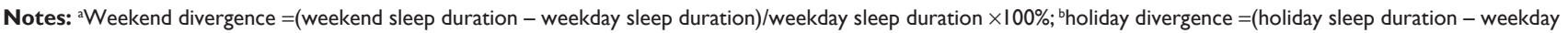
sleep duration)/weekday sleep duration $\times 100 \%$.

Abbreviations: DIS, difficulty initiating sleep; DMS, difficulty maintaining sleep; EMA, early morning awakening.

their sleep durations during weekends and holidays, but the overweight/obese children had lower weekend divergence ([weekend sleep duration - weekday sleep duration]/ weekday sleep duration $\times 100 \%$ ) and lower holiday divergence ([holiday sleep duration - weekday sleep duration]/ weekday sleep duration $\times 100 \%$ ) than their normal-weight peers. In addition, overweight/obese children were less prone to compensate for a lack of sleep during weekends (47.6\% vs $\left.39.1 \% ; \chi^{2}=11.637, P<0.001\right)$ and holidays $(52.0 \%$ vs $\left.42.0 \% ; \chi^{2}=16.057, P<0.001\right)$. Both groups shared similar prevalences of insomnia and its subtypes.

\section{Sleep duration during weekdays, weekends, and holidays and childhood overweight/obesity}

Table 4 exhibits individual increased adjusted odds ratios (ORs) of an overweight/obese status in association with short sleep durations during weekdays, weekends, and holidays. These differences between the groups with $\leq 8.00$ hours and 8.01-9.00 hours sleep and the group with $>10$ hours sleep during weekends and holidays reached statistical significance. However, no statistical significance was shown for sleep duration on weekdays. These logistic regression analyses were adjusted for age, sex, and suffering illness three or more times in the previous 12 months. In addition, multiple logistic regression analysis did not demonstrate interactions of the likelihood of being overweight/obese between weekday and weekend sleep duration or weekday and holiday sleep duration.

Table 4 Logistic regression results for the association between sleep durations (during weekdays, weekends, and holidays) and the risk of being overweight/obese in Chinese children

\begin{tabular}{|c|c|c|c|}
\hline & $\mathbf{n}$ & $\begin{array}{l}\text { Unadjusted OR } \\
(95 \% \mathrm{Cl})\end{array}$ & $\begin{array}{l}\text { Adjusted OR }{ }^{a} \\
(95 \% \mathrm{Cl})\end{array}$ \\
\hline \multicolumn{4}{|l|}{ Weekdays } \\
\hline$>10.00 \mathrm{~h}$ & 99 & 1.000 & 1.000 \\
\hline $9.01-10.00 \mathrm{~h}$ & 1,234 & $1.370(0.739-2.539)$ & $1.30 \mathrm{I}(0.874-1.936)$ \\
\hline $8.01-9.00 \mathrm{~h}$ & 1,491 & $1.297(0.70 \mathrm{I}-2.398)$ & $1.359(0.897-2.102)$ \\
\hline$\leq 8.00 \mathrm{~h}$ & 262 & $1.446(0.732-2.858)$ & $1.995(0.917-4.219)$ \\
\hline \multicolumn{4}{|l|}{ Weekends } \\
\hline$>10.00 \mathrm{~h}$ & 864 & $\mathrm{I} .000$ & 1.000 \\
\hline $9.01-10.00 \mathrm{~h}$ & 1,478 & $1.823(1.4 \mid 2-2.354)$ & $1.400(0.795-2.465)$ \\
\hline $8.0 \mathrm{I}-9.00 \mathrm{~h}$ & 645 & 2.049 (I.527-2.750) & $1.697(1.025-2.856)$ \\
\hline$\leq 8.00 \mathrm{~h}$ & 99 & 2.381 (1.387-4.089) & $2.69 \mid(1.5 \mid 3-4.785)$ \\
\hline \multicolumn{4}{|l|}{ Holidays } \\
\hline$>10.00 \mathrm{~h}$ & 1,092 & 1.000 & 1.000 \\
\hline $9.01-10.00 \mathrm{~h}$ & 1,435 & $1.838(1.455-2.322)$ & $1.5 \mathrm{I}(0.82 \mathrm{I}-2.808)$ \\
\hline $8.0 \mathrm{I}-9.00 \mathrm{~h}$ & 472 & $1.916(1.417-2.590)$ & $1.856(1.156-3.279)$ \\
\hline$\leq 8.00 \mathrm{~h}$ & 87 & $2.908(\mathrm{I} .697-4.98 \mathrm{I})$ & $2.921(1.630-5.323)$ \\
\hline
\end{tabular}

Note: aAdjusted for age, sex, and suffering illness three or more times in the previous 12 months.

Abbreviations: OR, odds ratio; $\mathrm{Cl}$, confidence interval; h, hours. 
Table 5 Logistic regression results for the association between sleep compensation during weekends and holidays and the risk of being overweight/obese in Chinese children

\begin{tabular}{|c|c|c|c|}
\hline & $\mathbf{N}$ & Unadjusted OR $(95 \% \mathrm{Cl})$ & Adjusted OR ${ }^{a}(95 \% \mathrm{Cl})$ \\
\hline \multicolumn{4}{|l|}{ Weekends } \\
\hline Compensated group ${ }^{b}$ & $\mathrm{I}, 40 \mathrm{I}$ & 1.000 & 1.000 \\
\hline Noncompensated group ${ }^{c}$ & $\mathrm{I}, 685$ & $1.4 \mid 4(1.158-1.725)$ & I.197 (1.004-1.493) \\
\hline \multicolumn{4}{|l|}{ Holidays } \\
\hline Compensated group ${ }^{d}$ & 1,559 & 1.000 & 1.000 \\
\hline Noncompensated group & 1,527 & $1.498(1.228-1.826)$ & $1.309(1.052-1.630)$ \\
\hline
\end{tabular}

Notes: ${ }^{a}$ Adjusted for age, sex, and suffering illness three or more times in the previous 12 months; ${ }^{b}$ weekend divergence $=[($ weekend sleep duration - weekday sleep duration)/weekday sleep duration $\times 100 \%] \geq 10 \%$; ${ }^{c}$ weekend divergence $=[($ weekend sleep duration - weekday sleep duration)/weekday sleep duration $\times 100 \%]<10 \%$;

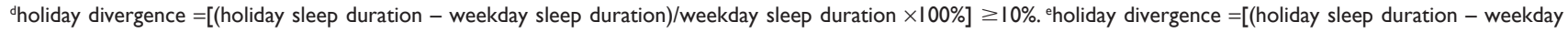
sleep duration)/weekday sleep duration $\times 100 \%]<10 \%$.

Abbreviations: $\mathrm{OR}$, odds ratio; $\mathrm{Cl}$, confidence interval.

\section{Sleep compensation and childhood overweight/obesity}

A logistic regression analysis was applied to the association between sleep compensation during weekends and holidays and the risk of being overweight/obese, which was adjusted for age, sex, and suffering illness three or more times in the previous 12 months (Table 5). The adjusted ORs for overweight/obesity were 1.197 (95\% confidence interval [CI]: 1.004-1.493) during weekends and 1.309 (95\% CI: 1.052-1.630) during holidays for the noncompensated group using the compensated group as a reference.

\section{Discussion}

This study investigated the association between the risk of being overweight/obese and sleep patterns during weekdays, weekends, and holidays in Chinese children aged 7-14 years. The association between this risk and sleep duration has been explored in numerous previous studies. ${ }^{10,11,26,27}$ However, to our knowledge, this study is the first of its kind to investigate the effect of sleep compensation on the risk of being overweight/obese in relationship to non-weekdays in children in mainland China.

A significant inverse dose-response relationship was demonstrated between the risk of being overweight/obese and sleep durations during weekends and holidays, which is consistent with the previous studies. ${ }^{21,22}$ Furthermore, sleep compensation during weekends and holidays ameliorated this risk. As mentioned previously, short sleep duration on workdays and extended sleep duration on non-workdays have been observed in many nations over the past decade. ${ }^{17-20}$ Mounting evidence demonstrates that the societal reductions in sleep may contribute to unhealthy consequences, especially metabolic abnormalities (eg, obesity and type- 2 diabetes mellitus) ${ }^{28}$ Therefore, whether the risk of unhealthy consequences can be ameliorated by catching up on sleep on weekends and holidays is hotly debated. A recent laboratory-based study examined five nights of 4-hour time in bed sleep restriction followed by two nights of recovery sleep of 8-hour time in bed in healthy males. ${ }^{29}$ Glucose levels did not significantly change after sleep restriction, but insulin and the glucose/insulin ratio increased. Glucose was reduced significantly compared to baseline after recovery, and insulin decreased toward the baseline; furthermore, leptin increased significantly with sleep restriction and remained elevated after recovery. These data suggest that sleep compensation repairs glucose metabolism and ameliorates the risk of obesity, which is supported by other laboratory-based studies. ${ }^{30,31}$ The current epidemiological study is most likely complementary to these laboratory-based studies: the overweight/obese children were less likely to compensate for a sleep debt on non-weekdays, and these children were more prone to suffer illness because of their potential metabolic abnormality.

The overweight/obese Chinese children preferred to retire and rise later on weekends or holidays, which might be synchronized with delayed melatonin release during their growth period..$^{32}$ This instability (extended sleep duration and delayed sleep phase during weekends) in the weekly sleep schedule is detrimental to sleep quality and daytime functioning. ${ }^{33} \mathrm{~A}$ consistent schedule is associated with a better-entrained circadian system, as measured through core temperature, and perceived quality of sleep. ${ }^{34}$ The circadian system is slow to adapt, and children with instability in weekly sleep schedule may experience constant fatigue and mental confusion that is similar to jet lag, which results in behavioral dysfunction. ${ }^{35}$ Therefore, sleep compensation on non-weekdays should not be recommended as an ideal way to eliminate the unhealthy consequences caused by insufficient sleep on weekdays, although it may ameliorate the risk of obesity/overweight.

Notably, the risk of being overweight/obese was not affected by sleep duration on weekdays in the current study, 
and no interaction of the risk of being overweight/obese was shown between weekday and non-weekday sleep durations. Short sleep duration was found to be an independent risk factor for the likelihood of being overweight/obese in most previous studies. ${ }^{10,11,21,22,26,27}$ A recent systematic review that established the international norm of sleep patterns in infants and children demonstrated that predominately, Asian countries report 1 hour less of sleep duration compared to non-Asian countries. ${ }^{36}$ Another study reported that Chinese children sleep almost 1 hour less per day than their American peers. ${ }^{25}$ Furthermore, in the current study, children in mainland China slept approximately a quarter of an hour less during weekdays compared with a study of primary school children in Hong Kong, a nearby Asian city. ${ }^{21}$ The People's Republic of China is a traditional Confucian country that has endorsed education throughout its history. In addition, Chinese parents usually place particular emphases on children's academic performance because of the unique one-child policy in recent decades. Therefore, most Chinese children spend an increasing amount of time on their studies and sacrifice sleep time on weekdays. ${ }^{37,38}$ It was reported that sedentary activities (eg, homework, reading, and screen viewing) are independently associated with overweight/obesity, ${ }^{21,22,27}$ but in the present study, overweight/obese children shared similar time allocations of their daily activities with normal-weight peers. This difference may be partially explained by the fact that Chinese children were under their parents' rigorous surveillance. We postulated that insufficient sleep on weekdays is pervasive in Chinese children, including overweight/obese children and normal-weight peers. Therefore, no significant association between sleep duration on weekdays and the risk of being overweight/obese was demonstrated in these Chinese children.

\section{Limitations}

Some limitations were noted in our study. The present study used a cross-sectional design, and causal relationships cannot be concluded between the risk of being overweight/ obese and sleep compensation on non-weekdays. This relationship should be investigated in further cohort studies. Second, children's body height and body weight were collected from parental reports, not anthropometric measurements. Third, compared with younger groups, there were very few children who were 13 years $(n=58)$ and 14 years of age $(n=6)$. This imbalance in the number of enrolled participants of different ages might be the reason for findings that overweight/obese children were younger. Fourth, sleep duration was calculated as the difference between get-up time and bedtime, which likely overestimated sleep duration in this database because of sleep latency and possible waking during sleep. Actiwatch (an objective instrument) might provide more accurate information on sleep duration. However, the use of Actiwatch was not practicable in this large-scale epidemiological study due to its excessive cost. The validity of parental reports of children's sleep duration was confirmed using actigraphy. ${ }^{39}$ Finally, some potential risk factors for pediatric overweight/obesity, such as family dietary habits and parental obesity, were not included in the current study.

\section{Conclusion}

The results of this study suggest that sleep compensation on non-weekdays ameliorates the risk of being overweight/ obese in Chinese children; however, sleep compensation should not be recommended as the ideal way to eliminate the unhealthy consequences caused by insufficient sleep on weekdays. Moreover, no significant association between the risk of being overweight/obese and sleep duration on weekdays was demonstrated in the current study, which is inconsistent with most previous studies. ${ }^{21,22}$ We postulated that this unique phenomenon may be due to the pervasive insufficient sleep on weekdays in Chinese children.

\section{Acknowledgments}

This work was supported by the Science and Technology Project Foundation of Science and Technology Department of Guangdong Province (Grant No: 2013B021800045), Guangdong Provincial Natural Science Foundation (Grant No: 2014A030313754), and Science and Technology Project Foundation of Guangzhou City (Grant No: 201510010215) to BZ.

\section{Author contributions}

BZ designed this study proposal, which was refined in discussions between all authors, and is the guarantor. YH carried out the analyses with statistical advice from BZ. Other authors (JZ, FJ, XL, YT, and HZ) participated in information collection from primary schools. All authors contributed toward data analysis, drafting and critically revising the paper and agree to be accountable for all aspects of the work.

\section{Disclosure}

The authors report no conflicts of interest in this work.

\section{References}

1. Freedman DS, Mei Z, Srinivasan SR, et al. Cardiovascular risk factors and excess adiposity among overweight children and adolescents: the Bogalusa Heart Study. J Pediatr. 2007;150(1):12-7.e2.

2. de Onis M, Blossner M, Borghi E. Global prevalence and trends of overweight and obesity among preschool children. Am J Clin Nutr. 2010; 92(5):1257-1264. 
3. Wang Y, Lobstein T. Worldwide trends in childhood overweight and obesity. Int J Pediatr Obes. 2006;1(1):11-25.

4. Shen T, Habicht JP, Chang Y. Effect of economic reforms on child growth in urban and rural areas of China. New Engl J Med. 1996;335(6): 400-406.

5. Zong XN, Li H. Physical growth of children and adolescents in China over the past 35 years. Bull WHO. 2014;92(8):555-564.

6. Sun $\mathrm{H}, \mathrm{Ma} \mathrm{Y}$, Han D, et al. Prevalence and trends in obesity among China's children and adolescents, 1985-2010. PloS One. 2014;9(8): e105469.

7. Popkin BM, Conde $\mathrm{W}, \mathrm{Hou} \mathrm{N}$, et al. Is there a lag globally in overweight trends for children compared with adults? Obesity (Silver Spring). 2006; 14(10):1846-1853.

8. Ickes MJ, McMullen J, Haider T, et al. Global school-based childhood obesity interventions: a review. Int J Environ Res Public Health. 2014; 11(9):8940-8961.

9. Budd GM, Hayman LL. Childhood obesity: determinants, prevention, and treatment. J Cardiovasc Nurs. 2006;21(6):437-441.

10. Chen X, Beydoun MA, Wang Y. Is sleep duration associated with childhood obesity? A systematic review and meta-analysis. Obesity (Silver Spring). 2008;16(2):265-274.

11. Marshall NS, Glozier N, Grunstein RR. Is sleep duration related to obesity? A critical review of the epidemiological evidence. Sleep Med Rev. 2008;12(4):289-298.

12. Taheri $\mathrm{S}$. The link between short sleep duration and obesity: we should recommend more sleep to prevent obesity. Arch Dis Child. 2006;91(11): 881-884.

13. Taheri S, Lin L, Austin D, et al. Short sleep duration is associated with reduced leptin, elevated ghrelin, and increased body mass index. PLoS Med. 2004;1(3):e62.

14. Halford JC, Harrold JA, Lawton CL, et al. Serotonin (5-HT) drugs: effects on appetite expression and use for the treatment of obesity. Curr Drug Targets. 2005;6(2):201-213.

15. Lucassen EA, Rother KI, Cizza G. Interacting epidemics? Sleep curtailment, insulin resistance, and obesity. Ann N Y Acad Sci. 2012;1264: $110-134$.

16. Matricciani LA, Olds TS, Blunden S, et al. Never enough sleep: a brief history of sleep recommendations for children. Pediatrics. 2012;129(3): $548-556$.

17. National Sleep Foundation. Sleep in America ${ }^{T M}$ Poll. 2009. Available from: http://sleepfoundation.org/sites/default/files/2009\%20POLL $\% 20$ HIGHLIGHTS.pdf. Accessed August 14, 2015.

18. Gradisar M, Gardner G, Dohnt H. Recent worldwide sleep patterns and problems during adolescence: a review and meta-analysis of age, region, and sleep. Sleep Med. 2011;12(2):110-118.

19. Ouyang F, Lu BS, Wang B, et al. Sleep patterns among rural Chinese twin adolescents. Sleep Med. 2009;10(4):479-489.

20. Kang V, Shao J, Zhang K, et al. Sleep deficiency and sleep health problems in chinese adolescents. Clin Med Insights Pediatr. 2012;6: 11-17.

21. Wing YK, Li SX, Li AM, et al. The effect of weekend and holiday sleep compensation on childhood overweight and obesity. Pediatrics. 2009;124(5):e994-e1000.
22. Kim CW, Choi MK, Im HJ, et al. Weekend catch-up sleep is associated with decreased risk of being overweight among fifth-grade students with short sleep duration. J Sleep Res. 2012;21(5):546-551.

23. Hao YL, Zhang B, Jia FJ, et al. A three-phase epidemiological study of short and long sleepers in a middle-aged Chinese population: prevalence and characteristics. Braz J Med Biol Res. 2014;47(2):157-165.

24. Group of China Obesity Task Force. Body mass index reference norm for screening overweight and obesity in Chinese children and adolescents. Zhonghua Liu Xing Bing Xue Za Zhi. 2004;25(2):97-102.

25. Liu X, Liu L, Owens JA, et al. Sleep patterns and sleep problems among schoolchildren in the United States and China. Pediatrics. 2005; 115(1 Suppl):241-249.

26. Chaput JP, Brunet M, Tremblay A. Relationship between short sleeping hours and childhood overweight/obesity: results from the 'Quebec en Forme' Project. Int J Obes (Lond). 2006;30(7):1080-1085.

27. Nixon GM, Thompson JM, Han DY, et al. Short sleep duration in middle childhood: risk factors and consequences. Sleep. 2008;31(1):71-78.

28. Cappuccio FP, D'Elia L, Strazzullo P, et al. Sleep duration and all-cause mortality: a systematic review and meta-analysis of prospective studies. Sleep. 2010;33(5):585-592.

29. van Leeuwen WM, Hublin C, Sallinen M, et al. Prolonged sleep restriction affects glucose metabolism in healthy young men. Int $J$ Endocrinol. 2010;2010:108641.

30. Spiegel K, Leproult R, L'Hermite-Baleriaux M, et al. Leptin levels are dependent on sleep duration: relationships with sympathovagal balance, carbohydrate regulation, cortisol, and thyrotropin. J Clin Endocrinol Metab. 2004;89(11):5762-5771.

31. Spiegel K, Leproult R, Van Cauter E. Impact of sleep debt on metabolic and endocrine function. Lancet. 1999;354(9188):1435-1439.

32. Copinschi G, Caufriez A. Sleep and hormonal changes in aging. Endocrinol Metab Clin North Am. 2013;42(2):371-389.

33. Biggs SN, Lushington $\mathrm{K}$, van den Heuvel CJ, et al. Inconsistent sleep schedules and daytime behavioral difficulties in school-aged children. Sleep Med. 2011;12(8):780-786.

34. Monk TH, Petrie SR, Hayes AJ, et al. Regularity of daily life in relation to personality, age, gender, sleep quality and circadian rhythms. J Sleep Res. 1994;3(4):196-205.

35. Wittmann M, Dinich J, Merrow M, et al. Social jetlag: misalignment of biological and social time. Chronobiol Int. 2006;23(1-2):497-509.

36. Galland BC, Taylor BJ, Elder DE, et al. Normal sleep patterns in infants and children: a systematic review of observational studies. Sleep Med Rev. 2012;16(3):213-222.

37. Li S, Arguelles L, Jiang F, et al. Sleep, school performance, and a school-based intervention among school-aged children: a sleep series study in China. PloS One. 2013;8(7):e67928.

38. Li S, Zhu S, Jin X, et al. Risk factors associated with short sleep duration among Chinese school-aged children. Sleep Med. 2010;11(9): 907-916.

39. Sekine M, Chen X, Hamanishi S, et al. The validity of sleeping hours of healthy young children as reported by their parents. $J$ Epidemiol. 2002;12(3):237-242.
Neuropsychiatric Disease and Treatment

\section{Publish your work in this journal}

Neuropsychiatric Disease and Treatment is an international, peerreviewed journal of clinical therapeutics and pharmacology focusing on concise rapid reporting of clinical or pre-clinical studies on a range of neuropsychiatric and neurological disorders. This journal is indexed on PubMed Central, the 'PsycINFO' database and CAS,

\section{Dovepress}

and is the official journal of The International Neuropsychiatric Association (INA). The manuscript management system is completely online and includes a very quick and fair peer-review system, which is all easy to use. Visit http://www.dovepress.com/testimonials.php to read real quotes from published authors. 